\title{
Integrating Youth Mental Health into Cash Transfer Programmes in response to the COVID-19 Crisis in Low- and Middle-income Countries
}

\section{Summary}

Social protection measures can play an important role in securing livelihoods, and in mitigating short- and long-term economic, social and mental health impacts of the COVID-19 pandemic. In particular, cash transfer programmes are currently being adapted or expanded in various low- and middle-income countries to support individuals and families during the pandemic. We argue that the current crisis offers an opportunity for these programmes to focus on vulnerable young people, including those with mental health conditions. Young people living in poverty and with mental health problems are at particular risk of experiencing adverse health, wellbeing and employment outcomes with long-term consequences. They are also at particular risk of developing mental health conditions during this pandemic. In order to support this population, cash transfer programmes should not only address urgent needs around food security and survival but expand their focus to address longer-term mental health impacts of pandemics and economic crises. Such an approach could help support young people's future life chances and break the vicious cycle between mental illness and poverty that spirals many young people into both socio-economic and mental health disadvantage.

\section{Young people's mental health during crises}

Many young people (aged 15 to 24) living in low- and middle-income countries (LMICs) are experiencing the full force of the virus and the consequences of the lockdown, often with limited support from social or other government programmes. With less access to social welfare safety nets, COVID-19 lockdowns, social distancing and other measures pose much greater threats to livelihoods and survival in LMICs than in high-income countries. ${ }^{1}$ Evidence from past crises and economic shocks suggests that mental health and economic impacts endure well beyond the crisis period. ${ }^{2-6}$ For example, suicide rates can remain high for years after the crisis ends, ${ }^{4}$ a trend which has been linked to persistent unemployment rates. ${ }^{7}$ Young people, including those with pre-existing mental health conditions, may be especially vulnerable to the impacts of crises, such as pandemics. Evidence from economic 
crises shows that they are more likely to take high risk jobs, in which they experience violence and exploitation, ${ }^{6}$ and that they are more likely than others to experience long-term unemployment after an economic crisis. ${ }^{6}$ They are much less likely to have financial savings or other assets that help them mitigate the impact of the crises.

Evidence from pandemics shows that being confined to a small space and not being able to maintain school and regular social connections can lead to various negative mental health impacts for young people ${ }^{8}$ exacerbated for those with existing mental health conditions, ${ }^{8}$ and those living in poverty. ${ }^{9,10}$ In LMICs, where young people represent a fifth of the total population, ${ }^{11}$ the impacts of the current crisis could strongly influence countries' future economic growth. ${ }^{12}$ Thus, there are strong economic arguments for governments to support young people's economic circumstances and also their mental health. ${ }^{13}$

\section{The role of cash transfer programmes in supporting youth mental health}

Evidence suggests that cash transfer programmes (CTPS) and other social protection measures such as social benefits, access-to-fair-credit schemes and active labour market programmes can improve mental health ${ }^{14-18}$ and reduce suicide rates. ${ }^{19-22}$ Among young people, evidence suggests that CTPs in Eastern Africa reduced symptoms of depression by as much as 38 percent. ${ }^{23-25}$ Mechanisms involve multiple pathways. For example, by providing material support to attend school or participate in social or leisure activities, CTPs can help young people to be more confident or assertive, and feel positive about their future. ${ }^{18,26-28}$ Programmes can also have wider spill-over effects on communities' social capital, thus

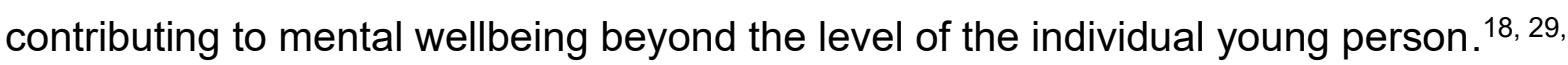
30 In response to COVID-19, some LMICs expanded their social protection measures including CTPS. In addition to providing emergency aid, many countries have made modifications to existing CTPs, allowing them to build on their infrastructure and administrative resources. Preliminary evidence suggests that from a total of 559 social assistance measures taken in response to COVID-19 in 168 countries worldwide, half relate to expansions of CTPs. ${ }^{31}$

Table 1 presents four examples of how large programmes have adapted to the current situation. The example CTPs are from three upper middle-income countries (Brazil, Colombia and South Africa), all of which are marked by high levels of 
inequality. The example CTPs were chosen as the research team is currently conducting a large multi-site study in those countries (CHANCES-6;

http://www.Ise.ac.uk/cpec/chances-6), which investigates the impacts of those programmes on youth mental health and life chances. The information was provided by research partners based in those countries, and includes data from information sources available to partners, complemented by publicly available data from websites of international organisations such the World Bank, and published literature. All four programmes have expanded vertically (i.e. increasing payments to existing programme beneficiaries) and three also expanded horizontally (i.e. increasing population coverage) in response to COVID-19. In addition to modifications made to existing CTPs, emergency aid programmes have been introduced in all three countries, which cover populations who are not programme beneficiaries of CTPs. In some instances those emergency programmes (e.g. "Ingreso solidario" in Colombia, "Auxílio emergencial" in Brazil, and "Special COVID19 Social Relief of Distress Grant" in South Africa) have built on the existing infrastructure and processes of CTPs. For example, they utilise their infrastructure for targeting and delivery of programmes by taking data from available registries to define their new target populations and by using existing (digital) payment systems for processing and delivery of payments. At the same time, some of these emergency aid programmes (e.g. "Auxílio emergencial") also developed new technologies (Apps) to reach out to populations not previously registered.

Those developments support the more general trend for CTPs to become a key social protection measure for many LMICs. ${ }^{32}$ Yet, many of these programmes do not specifically address the mental health-related needs or vulnerabilities of young people and their long-term mental health. While conditional CTPs seek to incentivise human capital investments in early life and adolescence, they often do not target young people directly, and cash is usually given to the primary caregiver. ${ }^{33,} 34 \mathrm{An}$ example of a CTP that specifically addresses the mental health-related needs of young people is the Colombian 'Jóvenes en Acción' ('Youth in Action'), which offers direct monthly payments to young people for attending and completing education programmes (Table 1). Programme components include those of mental health promotion, which offer learning modules that teach self-regulation and other socioemotional skills. Whilst its impact on mental health has not yet been assessed, 
findings from its evaluation (conducted before the pandemic) suggest that it can effectively improve their chances of entering formal employment, ${ }^{35}$ which is a likely contributor to improved long-term mental health.

\section{Challenges and opportunities for integrating mental health into cash transfer programmes}

Inevitably during crises, policy makers prioritise the most immediate concerns, such as providing food and medical care to those at risk of malnutrition and physical illness. Mental health is typically given lower priority, in part because it is perceived to have less immediate impact on mortality (other than suicide). ${ }^{36}$ Even when policy makers are aware that poor mental health is more costly than most other major noncommunicable diseases, ${ }^{37}$ they might not invest in mental health. Often influenced by misconceptions about mental health, historical underfunding and bureaucracy, they may not wish to divert limited health system resources away from existing priorities. At the same time, health policy makers might not be aware of the impacts that CTPs can have on mental health, and that programmes - although not always intentionally - might address many social determinants of mental health. ${ }^{38}$

However, crises also present opportunities to change systems and priorities. Experiences from past emergencies show that mental health can become a priority of system reform. ${ }^{39}$ International organisations have called for more attention and system wide responses to youth mental health during the COVID-19 crisis globally. 40, 41 To be effective, responses will require different sectors to come together, potentially sharing resources and agreeing common objectives, for instance working across social welfare or protection, employment and health spheres. This offers opportunities to look beyond the immediate crisis and also promote long-term economic and mental health resilience in line with the Sustainable Development Goals. $^{43}$

\section{Recommendations for integrating mental health into cash transfer programmes}

Based on evidence from evaluations of CTPs and of mental health responses to pandemics, we outline several principles and opportunities for integrating mental health into CTPs. Underlying these recommendations is a definition of mental health that follows the one of the Lancet Commission on global mental health, which 
considers problems on "a continuum from mild, time-limited distress to chronic, progressive, and severely disabling conditions", ${ }^{44}$ and which emphasises the need for interventions that range from promoting mental health and wellbeing and preventing mental health problems to treatment and rehabilitation. ${ }^{44}$

\section{$\underline{\text { Recommendation 1: }}$}

CTPs should target vulnerable young people at risk of or living with mental health conditions. Established welfare and social protection structures could be used to identify young people at risk of developing mental health conditions during or after the pandemic without a need to invest in formal mental health assessment procedures. Lessons from CTPs that have targeted vulnerable young people, including those with a disability or who are orphans, highlight the viability of doing so, for example using existing community routes such as local child protection committees. ${ }^{23,34}$ Recent innovations have been developed to identify clusters of population risk factors for example through the Identifying Depression Early in Adolescence (IDEA) tool in Brazil and Nepal, ${ }^{45}$ which confer greater vulnerability than any one risk factor. However, in order to specifically target young people with pre-existing mental health conditions, mental health care or welfare systems need to be strengthened in line with international law, and World Health Organization (WHO) best practice recommendations. ${ }^{46}$ Advocacy is needed to include mental health conditions as conferring eligibility for CTPs, under the umbrella of broader definitions of vulnerability or disability related criteria.

Digital technologies might also offer opportunities to reach young people who might otherwise not access programmes, for which they are eligible (for example, because their mental health condition made access difficult for them, or because of lack of transport). Surveys conducted of those aged 18 years or older in 11 LMICs across four global regions show that the vast majority (about 90\%) have their own, or access to a mobile phone; and about half of those are smartphones. ${ }^{47}$ Another study by the same research institution found that globally - including in LMICs - young people are more much more likely to have smartphones, access to internet and social media. ${ }^{48}$ Various tools exist from low cost ones that largely build on existing technologies (e.g. SMS) to comprehensive products that have been specifically 
designed for CTPs, and that include various functions (e.g. electronic payments, managing conditionalities, providing updates). However, these efforts need to complement other mechanisms, and build on existing welfare system structures as not all vulnerable individuals are able to access or use such technologies, ${ }^{49}$ and they can be potentially costly and difficult to implement. ${ }^{31,50}$

\section{Recommendation 2:}

CTPs should explore provision of resources to support mental health and nonstigmatising information about COVID-19. Evidence from previous and current pandemics suggest that misinformation and stigma about the pandemic present great threats to mental wellbeing, and can lead to social exclusion of the bereaved or those believed to have been in close contact with infected people. ${ }^{51}$ Whilst this relates to all populations, in some countries or settings young people might be particularly vulnerable to misinformation and stigma as they might not have the capacity to handle the frequency or to analyse the accuracy of information shared via social media. ${ }^{52,53}$ Providing accurate, up-to-date and non-stigmatising information about COVID-19, as well as increasing mental health literacy and signposting to locally relevant community support and resources, is an important part of an effective mental health response. ${ }^{54,55}$ As staff employed by CTPs or other welfare programmes are in contact with recipients (either personally or via digital technologies), they are well-placed to share relevant information and resources. Mobile phone texting is commonly used by CTPs to disseminate information. In addition, some large CTPs have well established and active social media platforms. For example the Colombian Jóvenes en Acción has 50,000 followers on twitter. Both channels can be used to provide up-to-date and accurate messages about COVID19 and about mental health promotion. This might include signposting to national mental health self-help lines, websites with mental health resources, or local community groups (as and when those are reopening). Donors also have an important role in this. For example, UNICEF has provided USD 13 million to fund programmes that facilitate access to learning for children and young people and specifically requests that programmes should incorporate anti-stigma (related to COVID-19) and mental health promotion messages. ${ }^{56}$

\section{Recommendation 3:}


CTPs should consider opportunities for increasing access to mental health support for young people. This means strengthening access to mental health interventions, as well as potentially, where resources and infrastructure permit, offering mental health interventions or components as part of CTPs. Programmes can be designed to facilitate access to support concerned with promotion, prevention and treatment. As part of preventative efforts, universal programmes that incorporate interpersonal skills and emotion regulation elements have shown to improve young peoples' mental health. ${ }^{57}$ Experiences from CTPs highlight the importance of teaching young people coping skills that help them to pursue educational or employment goals despite their challenging circumstances. ${ }^{34}$ As mentioned above the Colombian Jóvenes en Acción' is an example of a CTP that incorporates such mental health components. In addition, as countries come out of lockdown, there are opportunities for CTPs to include social integration programmes for youth. Whilst evidence on cross-sector responses to pandemics is scarce, some promising effects on youth mental health have been associated with community programmes focused on arts, play and sport. ${ }^{51}$ Those were implemented after the acute phase of the Ebola crisis to facilitate the social (re-)inclusion of young people, who had become orphaned or for other reasons socially excluded during the pandemic. The potential benefits of combining financial support with treatment have been suggested by a trial in Liberia, which found that an integrated cash transfer and cognitive-behaviour-therapy intervention led to reductions in criminal behaviour and improved self-control among young, unemployed men. ${ }^{58}$ Whilst such intervention requires additional investment of human and financial resources, they might be provided by trained community or lay health workers to increase feasibility. ${ }^{59}$

\section{Recommendation 4:}

Evaluations of CTPs should include an assessment of their mental health impact. Previous evaluations of CTPs have focused on capturing internalising problems through measures of depression or anxiety (such as the Centre for Epidemiological Studies and Depression Scale), as well on capturing suicide rates. ${ }^{20}$ Measures of general psychological distress, such as the Self-reporting Questionnaire (SRQ-20) or General Health Questionnaire (GHQ-12), have been widely used with young populations and can allow comparisons across different settings. ${ }^{60,61}$ However, there is also evidence that programmes might have an impact on externalising problems 
and anti-social behaviours such as crime or violence, ${ }^{58}$ which have substantial longterm social and economic impacts for individuals and society. ${ }^{62}$ More general indicators of mental wellbeing, such as Warwick and Edinburgh Mental Wellbeing Scale (WEMWBS) or quality of life, such as the Child Health Utility 9D Index, might be useful for assessing mental health promotion components of CTPs. These dimensions are important to capture as they improve coping with stress and are linked with future economic outcomes. ${ }^{63}$ Most of these measures can be used as self-report questionnaires and completed using digital technologies, and might therefore be feasible to assess during lockdown. In countries where lockdown measures are changing frequently or vary geographically, questions on the current lockdown situation could be included in the questionnaires, to help understand the influence on mental health. Whilst remote assessments are the only option available during lockdown, there are limitations of this method, in particular due to unequal access among those with low educational and socio-economic status. ${ }^{48}$ Changes to methods might need be adapted to include face-to-face assessments after the acute phase of pandemic, and comparisons will need to bear in mind different methods of assessments.

\section{Recommendation 5:}

Mental health impacts should be considered when making decisions about the amount, duration and administration of CTPs. For example, irregular payments can lead to increased stress among youth, ${ }^{64}$ and longer duration of payments may reduce depression among young people. ${ }^{32}$ As payments are currently being changed i.e. the amounts and method of access are modified (Table 1), clear communication about the nature of such changes might avoid increased stress. Whilst conditionalities incentivise behaviour (e.g. school attendance when lockdown restrictions are not in place) that might lead to improved mental health, conditionalities can also adversely impact psychological distress if they are difficult to achieve for the young person, and if the amount at risk presents an important proportion of the family's income. ${ }^{24}$ Since most programmes have removed their conditionalities during lockdown (Table 1), there are opportunities to consider alterations to conditionalities, or the way they are administered in the future, which could promote better mental health. 
The extent to which recommendations are applicable and can be implemented will depend on contextual factors in countries such as the existing infrastructure for mental health care, welfare systems and other sectors such as education, as well as the characteristics and nature of CTPs. The availability of digital infrastructure is another factor. In countries, in which CTPs are the main or only social protection measure, some of which will be run with very limited infrastructure, it might still be feasible to implement some light touch changes such as revising eligibility thresholds (recommendation 1) or providing accurate and up-to-date messages about COVID19 and about mental health promotion and prevention (recommendation 2). In countries that have some resources for providing mental health interventions, recommendation 3 can be considered. Such provision does not necessarily require specialist mental health professionals but can be provided by trained community workers or volunteers.

Similarly, recommendations apply differently for countries or regions depending on the state of the pandemic they are in. For example, recommendation 4 is likely to play a more important role during the acute phase of the pandemic, whilst recommendations 3 and 5 might become more relevant as countries come out of lockdown. However, as lockdown might be a long-term or repeating reality for some regions or countries, alternative methods for providing mental health components (for example, via phone or online) might need to be explored. Decision makers need to reflect carefully about their current situation and possible future scenarios with regards to the pandemic to decide how they can operationalise those recommendations in their specific context.

\section{Conclusion}

There are compelling reasons to integrate mental health into social protection programmes, particularly for young people. Mental health is unlikely to be seen as a priority when designing social protection policies. However, there is an opportunity now to highlight just how important mental health is to the current and future economic wealth of countries, and to highlight the benefits of addressing mental health and poverty simultaneously. ${ }^{65-67}$ Health policy makers might make a more convincing case for action using language which also resonates with finance 
ministries and international donors: protecting the mental health of youth is vital for future economic growth. Fundamentally, there is also an opportunity to think about the role of social protection schemes beyond the immediate crisis.

Whilst politicians need to make immediate decisions, it is equally important to collect evidence during crises and draw from existing evidence, and ongoing research. An example is the before mentioned research project CHANCES-6, which seeks to unpack some of the mechanisms by which CTPs influence the mental health and life chances of young people in six countries in Latin America and sub-Saharan Africa. This knowledge could inform responses to the COVID-19 pandemic that can mitigate the long-term economic and mental health consequences that will follow.

Contributors

$A B$ and SEL conceptualised the manuscript, with additions by EG, DM, MP, PH, YD. $A M, A P, A Z, C P, C L, C Z, P M, R A$ contributed with relevant country or topic specific information, and provided general feedback.

Declaration of interest

We declare no competing interests. 
References

1. Cash R, Patel V. Has COVID-19 subverted global health?. Lancet. 2020;395:1687-1688.

2. Evans-Lacko S, Knapp M, McCrone P, Thornicroft G, Mojtabai R. The mental health consequences of the recession: economic hardship and employment of people with mental health problems in 27 European countries. PLoS One. 2013;8:e69792.

3. Jalloh MF, Li W, Bunnell RE, Ethier KA, et al. Impact of Ebola experiences and risk perceptions on mental health in Sierra Leone, July 2015. BMJ Global Health. 2018;3:e000471.

4. Friedman J, Thomas D. Psychological Health Before, During, and After an Economic Crisis: Results from Indonesia, 1993 - 2000. World Bank Econ Rev. 2009;23:57-76.

5. Men T, Brennan P, Boffetta P, Zaridze D. Russian mortality trends for 1991-2001: analysis by cause and region. BMJ. 2003;327:964.

6. Marcus R, Gavrilovic M. The Impacts of the Economic Crisis on Youth:

Review of Evidence. London: Overseas Development Institute.

2010.https://assets.publishing.service.gov.uk/media/57a08b1740f0b64974000970/60 828_Youth-Evidence-Review-Final.pdf. Last accessed: 21 July 2020

7. Chang S-S, Gunnell D, Sterne JAC, Lu T-H, Cheng ATA. Was the economic crisis 1997-1998 responsible for rising suicide rates in East/Southeast Asia? A time-trend analysis for Japan, Hong Kong, South Korea, Taiwan, Singapore and Thailand. Soc Sci Med. 2009;68:1322-31.

8. Lee J. Mental health effects of school closures during COVID-19. Lancet Child \& Adolesc Health. 2020;4:421.

9. Save the Children. Children at Risk of Lasting Psychological Distress from Coronavirus Lockdown. https://zenit.org/articles/children-at-risk-of-lastingpsychological-distress-from-coronavirus-lockdown/2020 Last accessed: 21 July 2020 10. Guan H, Okely AD, Aguilar-Farias N, et al. Promoting healthy movement behaviours among children during the COVID-19 pandemic. Lancet Child \& Adolesc Health. 2020;4:416-8.

11. United Nations. World Population Prospects 2017. New York: UN Department for Economic and Social Affairs (UN DESA), Population Division; 2017. 12. Karlsson M, Nilsson T, Pichler S. The impact of the 1918 Spanish flu epidemic on economic performance in Sweden: an investigation into the consequences of an extraordinary mortality shock. J Health Econ. 2014;36:1-19. 13. Knapp M, Evans-Lacko S. Health economics. Rutter's Child and Adolescent Psychiatry 2015. p. 227-38.

14. Avendano M, Berkman LF, Brugiavini A, Pasini G. The long-run effect of maternity leave benefits on mental health: evidence from European countries. Soc Sci Med. 2015;132:45-53.

15. Ozer EJ, Fernald LC, Weber A, Flynn EP, VanderWeele TJ. Does alleviating poverty affect mothers' depressive symptoms? A quasi-experimental investigation of Mexico's Oportunidades programme. Int $J$ Epidemiol. 2011;40:1565-76.

16. Martorano B, Handa S, Halpern C, Thirumurthy H. Subjective Well-being, Risk Perceptions and Time Discounting: Evidence from a large-scale cash transfer programme. Innocenti; 2014. https://www.unicef-irc.org/publications/717- 
subjective-well-being-risk-perceptions-and-time-discounting-evidence-from-alarge.html. Last accessed: 7 June 2020

17. Pega F, Liu SY, Walter S, Pabayo R, Saith R, Lhachimi SK. Unconditional cash transfers for reducing poverty and vulnerabilities: effect on use of health services and health outcomes in low- and middle-income countries. Cochrane Database Syst Rev. 2017;11:Cd011135.

18. Attah R, Barca V, Kardan A, MacAuslan I, Merttens F, Pellerano L. Can Social Protection Affect Psychosocial Wellbeing and Why Does This Matter? Lessons from Cash Transfers in Sub-Saharan Africa. J Dev Stud. 2016;52:111531.

19. Stuckler D, Basu S, Suhrcke M, Coutts A, McKee M. The public health effect of economic crises and alternative policy responses in Europe: an empirical analysis. Lancet. 2009;374:315-23.

20. Alves FJO, Machado DB, Barreto ML. Effect of the Brazilian cash transfer programme on suicide rates: a longitudinal analysis of the Brazilian municipalities. Soc Psychiatry Psychiatr Epidemiol. 2019;54:599-606.

21. Cylus J, Glymour MM, Avendano M. Do generous unemployment benefit programs reduce suicide rates? A state fixed-effect analysis covering 19682008. Am J Epidemiol. 2014;180:45-52.

22. Avendano $\mathrm{M}$, Moustgaard $\mathrm{H}$, Martikainen $\mathrm{P}$. Are some populations resilient to recessions? Economic fluctuations and mortality during a period of economic decline and recovery in Finland. Eur $J$ of Epidemiol. 2017;32:77-85. 23. Kilburn K, Thirumurthy $\mathrm{H}$, Halpern CT, Pettifor A, Handa S. Effects of a Large-Scale Unconditional Cash Transfer Program on Mental Health Outcomes of Young People in Kenya. Journal Adolesc. 2016;58:223-9.

24. Baird SdH, Jocobus; Ozler, Berk. Income shocks and adolescent mental health. Washington DC; 2011.

25. Angeles G, de Hoop J, Handa S, Kilburn K, Milazzo A, Peterman A. Government of Malawi's unconditional cash transfer improves youth mental health. Soc Sci \& Med. 2019;225:108-19.

26. Handa S, Halpern CT, Pettifor A, Thirumurthy $H$. The government of Kenya's cash transfer program reduces the risk of sexual debut among young people age 15-25. PloS one. 2014;9:e85473-e.

27. Haushofer J, Shapiro J. Household, Response to Income Changes: Evidence from an Unconditional Cash Transfer Program in Kenya. Massachusetts Institute of Technology, Cambridge, MA; 2013.

28. Jones N, Abu-Hamad B, Pereznieto P, Sylvester K. Transforming Cash Transfers: Citizens' Perspectives on the Politics of Programme Implementation. J Dev Stud. 2016;52:1207-24.

29. Pavanello S, Watson C, Onyango-Ouma W, Bukuluki P. Effects of Cash Transfers on Community Interactions: Emerging Evidence. J Dev Stud. 2016;52:1147-61.

30. Attanasio O, Pellerano L, Reyes SP. Building Trust? Conditional Cash Transfer Programmes and Social Capital. Fiscal Studies. 2009;30:139-77.

31. Gentilini U, Almenfi M, P D, Demarco G, Santos I. Social Protection and Jobs Responses to COVID-19: A Real-Time Review of Country Measures.

https://socialprotection.org/discover/publications/social-protection-and-jobsresponses-covid-19-real-time-review-country. Last accessed: 7June 2020.

32. Beegle K, Coudouel A, Monsalve Montiel E. Realizing the Full Potential of Social Safety Nets in Africa. World Bank Group; Washington D.C. 2018. 
http://documents.worldbank.org/curated/en/657581531930611436/Realizing-theFull-Potential-of-Social-Safety-Nets-in-Africa. Last accessed: 7 June 2020.

33. UNICEF. Including Children in Policy Responses to Previous Economic Crises: The Case of Mexico's 1995 Peso Crisis and Argentina's 2002 Convertibility Crisis. United Nations Children's Fund, New York 2010.

34. Abu-Hamad B, Jones N, Pereznieto P. Tackling children's economic and psychosocial vulnerabilities synergistically: How well is the Palestinian National Cash Transfer Programme serving Gazan children?. Child Youth Serv Rev. 2014;47:121-35.

35. Prosperidad Social DPS. Informe de la Evaluación de Impacto del Programa Jóvenes en Acción. 2017

http://centrodedocumentacion.prosperidadsocial.gov.co/Documentos $\% 202019 / \mathrm{JeA} / \mathrm{E}$ valuaciones/Evaluacio $\%$ CC $\% 81 \mathrm{n} \% 20 \mathrm{de} \% 20$ Impacto $\% 20$ del $\% 20$ Programa $\% 20 \mathrm{Jo} \%$ CC\%81venes\%20en\%20Accio\%CC\%81n-Resumen\%20ejecutivo\%20\%20Dic\%202017.pdf; Last accessed 21 July 2020

36. Wahlbeck K, McDaid D. Actions to alleviate the mental health impact of the economic crisis. World Psychiatry. 2012;11:139-45.

37. Bloom D, Cafiero, ET, Jané-Llopis E, et al. The Global Economic Burden of Noncommunicable Diseases. World Economic Forum, Geneva: 2011.

38. Lund C, Brooke-Sumner C, Baingana F, Baron EC, Breuer E, Chandra P, et al. Social determinants of mental disorders and the Sustainable Development Goals: a systematic review of reviews. Lancet Psychiatry. 2018;5:357-69. 39. WHO. Building back better: sustainable mental health care after emergencies. World Health Organization, Geneva: 2013.

40. World Economic Forum. A Global Framework for Youth Mental Health: Investing in Future Mental Capital for Individuals, Communities and Economies, World Economic Forum, Geneva: 2020.

http://www3.weforum.org/docs/WEF_Youth_Mental_Health_2020.pdf Last accessed 30 July 2020.

41. Rogers JP, Chesney E, Oliver D, et al. Psychiatric and neuropsychiatric presentations associated with severe coronavirus infections: a systematic review and meta-analysis with comparison to the COVID-19 pandemic. Lancet Psychiatry. 2020;7:611-627.

42. Burgess RA, Jain S, Petersen I, Lund C. Social interventions: a new era for global mental health? Lancet Psychiatry. 2019;7:118-119.

43. United Nations. Transforming our world: the 2030 Agenda for Sustainable Development; United Nations: 2015.

https://sustainabledevelopment.un.org/post2015/transformingourworld/. Last accessed 21 July 2020.

44. Patel V, Saxena S, Lund C, et al. The Lancet Commission on global mental health and sustainable development. Lancet. 2018;392:1553-98.

45. Brathwaite R, Rocha TB-M, Kieling C, et al. Predicting the risk of depression among adolescents in Nepal using a model developed in Brazil: the IDEA Project. [published online ahead of print, 2020 Mar 12]. Eur Child Adolesc Psychiatry. https://doi.org/10.1007/s00787-020-01505-8

46. Szmukler G, Daw R, Callard F. Mental health law and the UN Convention on the rights of Persons with Disabilities. Int J Law Psychiatry. 2014;37:245-52. 
47. Pew Research Center. Mobile Connectivity in Emerging Economies; 2019. https://www. pewresearch.org/internet/2019/03/07/mobile-connectivity-in-emergingeconomies/. Last accessed 20 July 2020

48. Pew Research Center. Smartphone Ownership Is Growing Rapidly Around the World, but Not Always Equally; 2019.

https://www.pewresearch.org/global/2019/02/05/smartphone-ownership-is-growingrapidly-around-the-world-but-not-always-equally/. Last accessed 20 July 2020.

49. Vaziralli S. A social protection response to COVID-19 in developing countries, 2020, https://www.theigc.org/wp-content/uploads/2020/04/Vazirelli-2020policy-brief.pdf. Last accessed 21 July 2020.

50. O'Brien C, Hove F, Smith G. Factors Affecting the Cost-Efficiency of Electronic Transfers in Humanitarian Programmes. Oxford Policy Management; 2013. https://policy-practice.oxfam.org.uk/publications/factors-affecting-the-costefficiency-of-electronic-transfers-in-humanitarian-p-322212; Last accessed 21 July 2020.

51. Cénat JM, Mukunzi JN, Noorishad P-G, Rousseau C, Derivois D, Bukaka J. A systematic review of mental health programs among populations affected by the Ebola virus disease. J Psychosom Res. 2020;131:109966.

52. Torales J, O'Higgins M, Castaldelli-Maia JM, Ventriglio A. The outbreak of COVID-19 coronavirus and its impact on global mental health. Int J Soc Psychiatry. 2020;66:317-20.

53. Sharma V, Reina Ortiz M, Sharma N. Risk and Protective Factors for Adolescent and Young Adult Mental Health Within the Context of COVID-19: A Perspective From Nepal. Journal Adolesc. 2020;67:135-7.

54. IASC. Interim Briefing Note Addressing Mental Health and Psychosocial Aspects of COVID-19 Outbreak, Inter-Agency Standing Committee; 2020. https://interagencystandingcommittee.org/iasc-reference-group-mental-health-andpsychosocial-support-emergency-settings/interim-briefing. Last accessed: 7 June 2020.

55. Moreno C, Wykes T, Galderisi S, et al. How mental health care should change as a consequence of the COVID-19 pandemic. [published online ahead of orint, 2020 July 16]. Lancet Psychiatry. https://doi.org/10.1016/S22150366(20)30307-2

56. UNICEF. UNICEF scales up support in 145 countries to keep children learning, as COVID-19 forces majority of schools worldwide to close, 2020. https://www.unicef.org/press-releases/unicef-scales-support-145-countries-keepchildren-learning-covid-19-forces-majority. Last accessed 7 June 2020.

57. Skeen S, Laurenzi CA, Gordon SL, et al. Adolescent Mental Health Program Components and Behavior Risk Reduction: A Meta-analysis. Pediatrics. 2019;144.

58. Blattman CJ, Julian C, Sheridan, M. Reducing Crime and Violence:

Experimental Evidence on Adult Noncognitive Investments in Liberia. World Bank Group, Washington D.C. 2016.

59. Patel V, Weobong B, Weiss HA, et al. The Healthy Activity Program (HAP), a lay counsellor-delivered brief psychological treatment for severe depression, in primary care in India: a randomised controlled trial. Lancet. 2017;389:176-85. 60. Liu J, Modrek S, Sieverding M. The mental health of youth and young adults during the transition to adulthood in Egypt. Demogr Res. 2017;36:172158. 
61. Netsereab TB, Kifle MM, Tesfagiorgis RB, Habteab SG, Weldeabzgi YK, Tesfamariam OZ. Validation of the WHO self-reporting questionnaire-20 (SRQ20) item in primary health care settings in Eritrea. Int $J$ Ment Health Syst. 2018;12:61.

62. Rivenbark JG, Odgers CL, Caspi A, et al. The high societal costs of childhood conduct problems: evidence from administrative records up to age 38 in a longitudinal birth cohort. J Child Psych Psychiatry. 2018;59:703-10. 63. Moffitt TE, Arseneault L, Belsky D, et al. A gradient of childhood selfcontrol predicts health, wealth, and public safety. Proceedings of the National Academy of Sciences. 2011;108:2693.

64. Eyal K. Follow the child: the effect of an unconditional cash transfer on adolescent human capital and mental health. University of Cape Town, Cape Town, 2016.

65. Lund C, Cois A. Simultaneous social causation and social drift: Longitudinal analysis of depression and poverty in South Africa. J Affect Disord. 2018;229:396-402.

66. Lund C, De Silva M, Plagerson S, et al. Poverty and mental disorders: breaking the cycle in low-income and middle-income countries. Lancet. 2011;378:1502-14.

67. Lund C, Breen A, Flisher AJ, Kakuma R, Corrigall J, Joska JA, et al. Poverty and common mental disorders in low and middle income countries: $A$ systematic review. Soc Sci Med. 2010;71:517-28. 
Affiliations

\section{i. Names of authors}

Annette Bauer ${ }^{1}$

Emily Garman ${ }^{2}$

David McDaid ${ }^{1}$

Mauricio Avendano Pabon 3,4

Philipp Hessel ${ }^{5}$

Yadira Díaz ${ }^{5}$

Ricardo Araya Baltra ${ }^{6}$

Crick Lund ${ }^{2,6}$

Paulo Malvasi ${ }^{7}$

Alicia Matijasevich ${ }^{8}$

A-La Park 1

Cristiane Silvestre Paula ${ }^{9}$

Carolina Ziebold ${ }^{9}$

Annie Zimmerman ${ }^{5}$

Sara Evans-Lacko ${ }^{1}$

\section{ii. Affiliations of the authors}

${ }^{1}$ Care Policy and Evaluation Centre, Department of Health Policy, London School of Economics and Political Science, London, United Kingdom

2 Alan J Flisher Centre for Public Mental Health, Department of Psychiatry and Mental Health, University of Cape Town, Cape Town, South Africa

${ }^{3}$ Global Health \& Social Medicine, King's College London, London, United Kingdom

4 Department of Social and Behavioural Sciences, Harvard School of Public Health Boston, Massachusetts, United States

${ }^{5}$ Escuela de Gobierno Alberto Lleras Camargo, Universidad de Los Andes, Bogotá, Colombia

${ }^{6}$ King's Global Health Institute, Centre for Global Mental Health, Health Service \& Population Research Department, Institute of Psychiatry, Psychology and Neuroscience, King's College London, London, United Kingdom

${ }^{7}$ Faculdade de Ciências Médicas da Santa Casa de São Paulo, Department of Public Health , São Paulo, Brasil 
${ }^{8}$ Faculdade de Medicina FMUSP, Departamento de Medicina Preventiva, Universidade de São Paulo, São Paulo, Brasil

9 Programa de Pós-graduação em Distúrbios do Desenvolvimento, Universidade Presbiteriana Mackenzie, São Paulo, Brasil

\section{iii. Author qualifications}
A Bauer (LSE, MSc)
E Garman (UCT, PhD)
D McDaid (LSE, MSc)

M Avendano Pabon (Havard School of Public Health \& King's College London, PhD, full professor)

P Hessel (Universidad de Los Andes, PhD)

Y Díaz (Universidad de Los Andes, PhD)

$\mathrm{R}$ Araya Baltra (King's College London, $\mathrm{PhD}$, full professor)

C Lund (UCT \& King's College London, PhD, full professor)

P Malvasi (Universidade de São Paulo, PhD)

A Matijasevich (Universidade de São Paulo, PhD)

A Park (LSE, MSc)

CS Paula (Universidade Presbiteriana Mackenzie, PhD)

C Ziebold (Universidade Presbiteriana Mackenzie, PhD)

A Zimmerman (King's College London, PhD)

S Evans-Lacko (King's College London, PhD) 